Tạp chí Các Khoa học về Trái Đất, 38 (1), 14-21

Viện Hàn lâm Khoa học và Công nghệ Việt Nam
Tạp chí Các Khoa học về Trái Đất
(VAST)
Website: http://www.vjs.ac.vn/index.php/jse

\title{
Về chuyển dịch vỏ Trái Đất dọc đới đứt gãy Sông Hồng từ số liệu GNSS
}

\author{
Vy Quốc Hải*, Trần Quốc Cường, Nguyễn Viết Thuận \\ Viện Địa chất, Viện Hàn lâm Khoa học và Công nghệ Việt Nam
}

Chấp nhận đăng: 15 - 3 - 2016

ABSTRACT

\section{Crustal movement along the Red River Fault zone from GNSS data}

\begin{abstract}
For the first time, recent crustal movement of the Red River Fault was investigated, discussed by segments, based on GNSS data of Thac Ba, Ba Vi - Tam Dao, and Ha Noi networks. Data acquired by the network were processed, movement characteristics of fault zones were synthesized and evaluated and results were achieved, (1) absolute crustal movement velocities of the study area are approximately $34 \mathrm{~mm} /$ year with east-southeast direction, (2) the Red River Fault has been relatively inactive in recent times, with a relative motion between two sides of the fault is approximately $1 \mathrm{~mm} /$ year. We propose that more measurement campaigns should be taken in order to determine the value and trend of movements more accurately.
\end{abstract}

Keywords: Red River Fault, crustal movement, GNSS data.

C2016 Vietnam Academy of Science and Technology

\section{Mở đầu}

Nghiên cứu chuyển dịch hiện đại các đới đứt gãy đã được tiến hành từ nhiều chuyên ngành khác nhau. Từ góc độ phương pháp định lượng, công nghệ GNSS (Global Navigation Satellite System Hệ thống vệ tinh dẫn đường toàn cầu) đã được ứng dụng ở Việt Nam từ những năm 1990. Các lưới GNSS đã được thiết lập, quan trắc và xử lý số liệu nhằm xác định chuyển dịch hiện đại một số đứt gãy trên lãnh thổ Việt Nam như: Sông Hồng, Sông Đà, Lai Châu - Điện Biên, Sông Mã, khu vực Thành phố Hồ Chí Minh, Ninh Thuận,... Tuy vậy, duy nhât dọc theo đới đứt gãy Sông Hồng (ĐGSH) đã thiết lập ba lưới: lưới Thác Bà, lưới Tam Đảo $\mathrm{Ba}$ Vì, lưới khu vực Hà Nội. Sơ đồ các lưới được trình bày ở hình 1 và một số đặc điểm của lưới được thông kê ở bảng 1 .

Theo (Nguyễn Đăng Túc, 2002), theo chiều từ

*Tác giả liên hệ, Email: vqhai75@yahoo.com bắc xuống nam, ĐGSH chia thành nhiều đoạn (đoạn Veixi-Midu; đoạn Midu-Manpan; ManpanViệt Trì; đoạn Việt Trì - Vịnh Bắc Bộ và đoạn Vịnh Bắc Bộ) có hoạt động địa động lực trong các điều kiện địa chất kiến tạo khác nhau. Hiện trạng ba lưới (thống kê ở bảng 1) đã tạo điều kiện hết sức thuận lợi để có góc nhìn sâu hơn về chuyển dịch hiện đại vỏ Trái đất dọc ĐGSH từ số liệu GNSS.

Để thực hiện ý tưởng trên, công trình này đã thu thập số liệu đo của các chu kỳ, xử lý bằng phần mềm Bernese 5.0 xác định các vec tơ vận tốc lưới khu vực Hà Nội. Bên cạnh đó sẽ sử dụng kết quả (vận tốc chuyển dịch của các mốc) từ các dự án, đề tài khác liên quan tới lưới Thác Bà (Ngô Văn Liêm, 2011), lưới Tam Đảo-Ba Vì (Vy Quốc Hải, 2009; Vy Quốc Hải và nnk, 2011) tiến hành thảo luận kết quả từ ba lưới riêng biệt nhằm đánh giá các đặc điểm chuyển dịch của ĐGSH thông qua việc phân tích độ lớn cũng như hướng của các vec tơ vận tốc. 


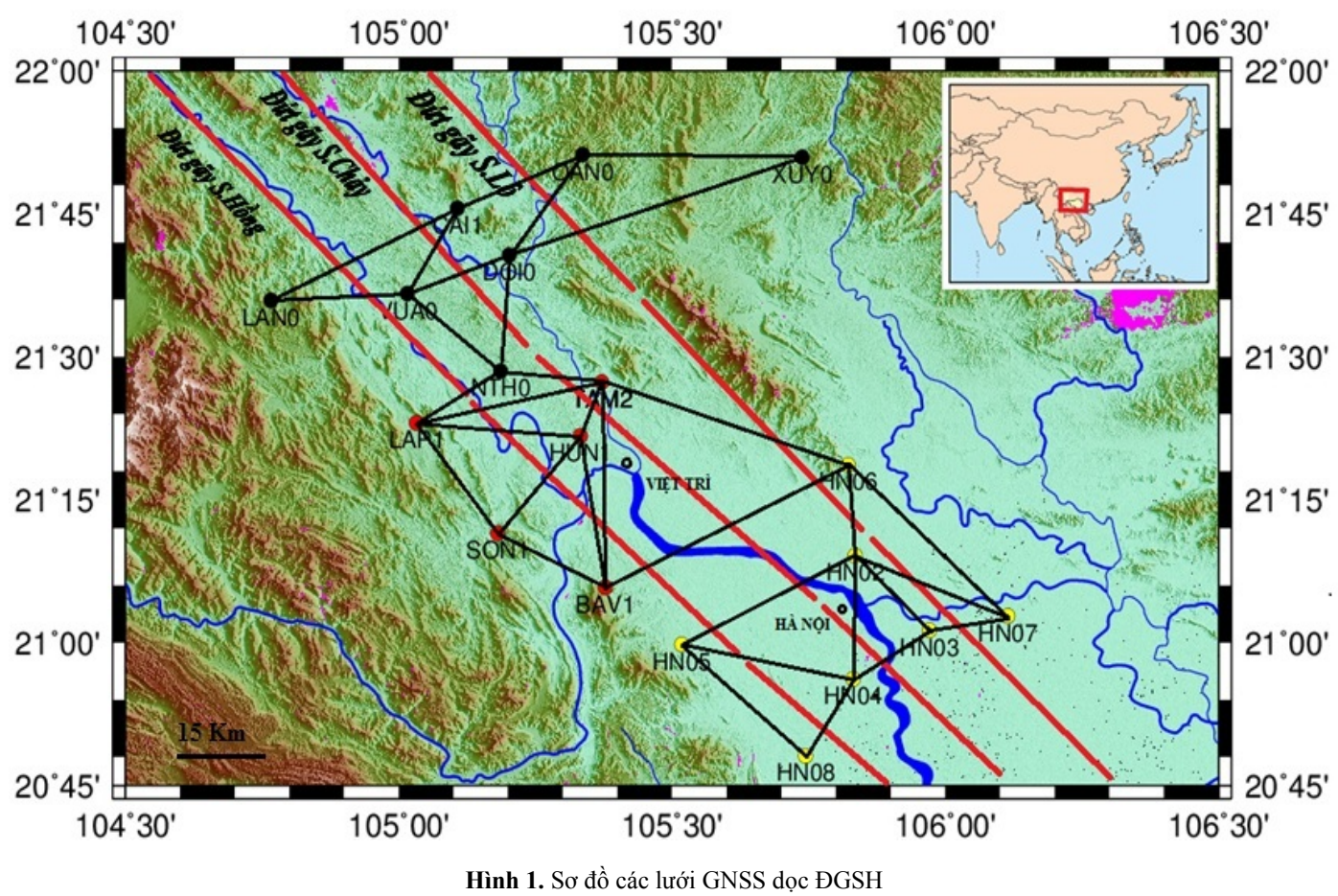

Bảng 1. Một số đặc điểm của các lưới dọc ĐGSH

\begin{tabular}{|c|c|c|c|}
\hline Tên lưới & Năm thiết lập & Số mốc & Số chu kỳ đo \\
\hline Thác Bà & 1994 & 7 & $1994,2000,2010$ \\
\hline $\begin{array}{l}\text { Tam Đảo- } \\
\text { Ba Vì }\end{array}$ & 1994 & 7 & $\begin{array}{l}1994,1996,1998,2000 \\
\text { và } 2006-2007\end{array}$ \\
\hline $\begin{array}{l}\text { Khu vực } \\
\text { Hà Nội }\end{array}$ & 2005 & 8 & $2005,2006,2013,2015$ \\
\hline
\end{tabular}

2. Xác định vec tơ chuyển dịch từ số liệu lưới khu vực Hà Nội

\subsection{Thiết lập lưới}

Lưới GNSS nghiên cứu chuyển dịch trên khu vực châu thổ Sông Hồng lân cận Hà Nội (sau đây được viết tắt là lưới Hà Nội) gồm 8 điểm được thiết lập năm 2005 (Nguyễn Tuấn Anh và nnk, 2006). Việc thiết lập lưới và thi công mốc được tiến hành dựa trên bản đồ địa chất và sơ đồ các đứt gãy tại khu vực. Khu vực nghiên cứu thuộc đoạn Việt Trì - Vịnh Bắc Bộ có chiều dài khoảng 160 $\mathrm{km}$, chiều rộng chừng $50-60 \mathrm{~km}$. Việc lựa chọn và xác định các vị trí mốc GNSS đã được Nguyễn Tuấn Anh và nnk, 2006 thực hiện đảm bảo các yêu cầu sau:

- Phân bố đều trên các cánh đứt gãy; có xác suất lớn nhất phản ảnh được chuyển dịch của đứt gãy;

- Bố trí nơi có nền đất chắc, ổn định; hạn chế ảnh hưởng của các tác động ngoại cảnh đến sự ổn định của mốc;

- Không được nằm trong vùng quy hoạch xây dựng và phát triển dân sinh, sao cho mốc có thể được bảo quản và tồn tại trong thời gian dài hàng chục năm.

- Phải chọn tại những nơi thuận lợi cho việc thu tín hiệu GNSS độ chính xác cao trong nhiều ngày liên tục, thuận lợi về việc trông coi máy móc, duy trì nguồn điện, không chịu ảnh hưởng của ngoại cảnh đến việc thu tín hiệu GNSS.

Tuy vậy, với khu vực chủ yếu là đồng bằng với các đặc điểm lớp phủ trầm tích dày hàng chục mét (không có khả năng xuất lộ đá gốc), mật độ dân cư cao, thảm thực vật dày nên việc bố trí mốc không hẳn là thuận lợi. Bởi vậy, mốc được thi công có bệ bê tông trên nền trầm tích với độ sâu cỡ 3 mét. Cho dù không gắn được vào đá gốc, song với 
Tạp chí Các Khoa học về Trái Đất, 38 (1), 14-21

phương án thi công này cũng hạn chế được phần lớn các yếu tố (mực nước ngầm, biến đổi nhiệt độ, độ ẩm) gây ra chuyển dịch ngoại sinh. Ăng ten thu tín hiệu được giải quyết bằng phương án định tâm bắt buộc trên trụ bê tông cao 2-3m. Với phương án này hạn chế sai số định tâm và nâng cao độ thông thoáng khi thu tín hiệu. Hai điểm HN05 và HN06 sử dụng mốc của lưới tam giác khống chế Nhà nước được thiết lập đã lâu (hàng chục năm) đảm bảo độ ổn định, an ten được dựng bằng chân máy và bộ định tâm quang học. Tổng cộng đã thiết lập 8 mốc được ký hiệu HN01 đến HN08 (hình 2).

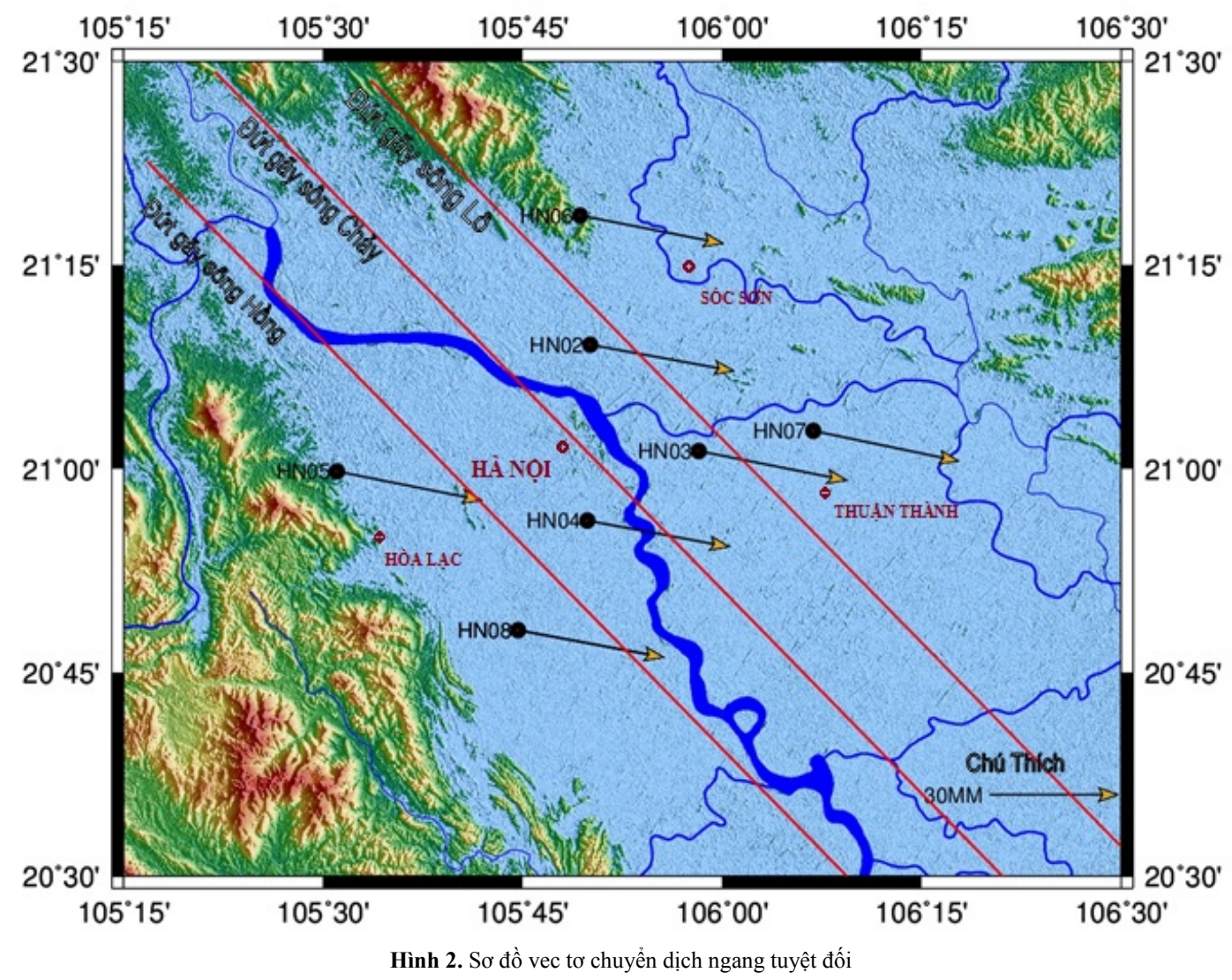

\subsection{Thu thập số liệu}

Lưới được đo theo bốn chu kỳ: 2005, 2006, 2013 và 2015 bằng máy thu 2 tần số. Số liệu được thu thập theo phương pháp đo tĩnh với tần suất ghi tín hiệu 30 giây. Ca đo có độ dài 24 giờ, được bắt đầu từ 7 giờ sáng ( 0 giờ $\mathrm{GMT})$, kết thúc trước 7 giờ ngày hôm sau; kiểm tra, chuẩn bị năng lượng và tiếp tục ca đo tiếp theo. Với phương án đo như vậy, tệp số liệu tương thích với số liệu của các điểm IGS (International GNSS Service) quốc tế và lịch vệ tinh chính xác, thuận lợi cho công đoạn xử lý. Cũng xin lưu ý, sau năm 2006, điểm HN01 không tồn tại nên các chu kỳ 2013 không thể thu tín hiệu ở điểm này. Chu kỳ 2015 chỉ quan trắc trên 4 điểm lần lượt là HN02, HN04, HN05 và HN07.

Số liệu đo ngoài thực địa sau khi kiểm tra chuyển về dạng Rinex. Dưới đây là bảng tổng hợp các tệp số liệu đo (bảng 2).

Tất cả các số liệu đo của 4 chu kỳ đã được tập hợp, kiểm tra đầy đủ sẵn sàng đưa vào xử lý. 
V.Q. Hải và nnk/Tạp chí Các Khoa học về Trái Đất, Tập 38 (2016)

Bảng 2. Bảng tổng hợp các tệp đo

\begin{tabular}{|c|c|c|c|c|c|c|c|c|c|c|}
\hline \multirow{2}{*}{ STT } & \multirow{2}{*}{ Năm } & \multirow{2}{*}{ DOY $^{*}$} & \multicolumn{8}{|c|}{ Điểm } \\
\hline & & & HNO1 & $\mathrm{HN} 02$ & $\mathrm{HN} 03$ & HNO4 & HNO5 & HN06 & HN07 & HN08 \\
\hline & 2005 & & & & & & & & & \\
\hline 1 & & 360 & $x$ & $\times$ & $x$ & $x$ & $x$ & $x$ & $x$ & $x$ \\
\hline 2 & & 361 & $x$ & $\times$ & $x$ & $\times$ & $\times$ & $x$ & $x$ & $x$ \\
\hline 3 & & 362 & $x$ & $x$ & $x$ & $x$ & $x$ & $x$ & $x$ & $\times$ \\
\hline & 2006 & & & & & & & & & \\
\hline 4 & & 299 & $x$ & $\times$ & $x$ & $x$ & $x$ & $x$ & $\times$ & $x$ \\
\hline 5 & & 300 & $x$ & $\times$ & $x$ & $x$ & $x$ & $x$ & $\times$ & $\times$ \\
\hline 6 & & 301 & $x$ & $x$ & $x$ & $x$ & $x$ & $x$ & $x$ & $x$ \\
\hline & 2013 & & & & & & & & & \\
\hline 7 & & 294 & & $x$ & $x$ & $x$ & $x$ & $x$ & $x$ & $x$ \\
\hline 8 & & 295 & & $x$ & $x$ & $x$ & $x$ & $x$ & $x$ & $x$ \\
\hline 9 & & 296 & & $\times$ & $x$ & $x$ & $x$ & $x$ & $x$ & $x$ \\
\hline 10 & & 297 & & $x$ & $x$ & $x$ & $x$ & $x$ & $\times$ & $x$ \\
\hline & 2015 & & & & & & & & & \\
\hline 11 & & 027 & & $x$ & & $x$ & $x$ & & $\times$ & \\
\hline 12 & & 028 & & $x$ & & $x$ & $x$ & & $x$ & \\
\hline 13 & & 029 & & $\times$ & & $x$ & $x$ & & $x$ & \\
\hline 14 & & 030 & & $\times$ & & $x$ & $\times$ & & $x$ & \\
\hline
\end{tabular}

Ghi chú: DOY-Day of Year: ngày trong năm, khái niệm quan trọng trong xử lý số liệu GPS

\subsection{Xử lý số liệu}

Số liệu 4 chu kỳ được xử lý bằng phần mềm Bernese 5.0 (Rolf Dach, Urs Hugentober and Peter Walser, 2008). Xử lý bằng phần mềm khoa học ngoài số liệu đo còn phải tập hợp nhiều số liệu của IGS và quốc tế nhằm hỗ trợ phần mềm hiệu chỉnh kết quả tính toán.

Số liệu đo đã trình bày ở phần trên, dưới đây là một số đặc điểm liên quan tới số liệu quốc tế. Số liệu quốc tế bao gồm: tệp số liệu đo, tọa độ, vận tốc của các điểm IGS lân cận Việt Nam nhằm xác định tọa độ chính xác trong ITRF (Khung quy chiếu Trái đất quốc tế - International Terrestial Reference Frame) và tính chuyển dịch tuyệt đối; lịch vệ tinh chính xác; các loại số liệu hỗ trợ khác.

\subsubsection{Số liệu đo của các điểm IGS}

- Hạ tầng thiết bị của các điểm này đạt chuẩn IGS, đảm bảo số lượng cũng như chất lượng số liệu, các thông tin minh bạch thuận lợi cho việc khai báo cho phần mềm xử lý.

- Có tọa độ với độ chính xác cao trong các hệ tọa độ toàn cầu, được công bố chính thức, có thể khai thác và sử dụng như số liệu chuẩn để xác định tọa độ và vận tốc với độ chính xác cao nhất có thể, đáp ứng các yêu cầu nghiên cứu chuyển dịch hiện đại.
- Từ các điểm IGS có thể khai thác và xử lý các ca đo liên tục ngày-đêm (độ dài ca đo 24 giờ) với số lượng ca đo đủ lớn, để có thể đạt độ tin cậy cao khi xử lý lưới khu vực.

Có thể khai thác số liệu IGS từ nhiều điểm khác nhau, tuy vậy các phần mềm đều khuyến cáo, nên khai thác ở các điểm lân cận khu vực nghiên cứu, sao cho độ dài cạnh nhỏ hơn 2000km.

\subsubsection{Lịch vệ tinh chinh xác}

Lịch vệ tinh quảng bá chỉ được sử dụng khi xử lý số liệu với cạnh nhỏ hơn $50 \mathrm{~km}$. Tất nhiên với khoảng cách lớn hơn phải khai thác và sử dụng lịch vệ tinh chính xác. Về lịch vệ tinh đã được đề cập trong rất nhiều tài liệu tham khảo trong và ngoài nước. Việc khai thác lịch vệ tinh chính xác được tiến hành từ các trang IGS hoặc các tổ chức quốc tế.

\subsubsection{Số liệu hỗ trợ}

Số liệu hỗ trợ gồm nhiều loại có cấu trúc khác nhau, khai thác từ nhiều nguồn trên các Web quốc tế. Cuối cùng xin lưu ý, tất cả các tệp số liệu đo, số liệu IGS và số liệu hỗ trợ đã được khai thác đầy đủ cho các đợt đo và các ngày đo, đảm bảo cho việc xử lý số liệu đạt độ chính xác và độ tin cậy cao.

Về nguyên lý, số liệu sẽ được xử lý theo ca đo (trong trường hợp của chúng ta là từng ngày), xác 
Tạp chí Các Khoa học về Trái Đất, 38 (1), 14-21

định tọa độ, từ đó tích hợp phương trình chuẩn của tất cả các ngày đo, xác định vận tốc chuyển dịch. Việc xử lý số liệu bằng phần mềm Bernese 5.0 được tiến hành theo các bước:

- Xủ lý theo tùng bước đến kết quả bình sai: Xử lý số liệu bằng phần mềm Bernese gồm các công đoạn: chuyển đổi số liệu sang dạng thích hợp với Bernese, chuyển đổi lịch vệ tinh, xác định sai số đồng hồ, thiết lập phương trình cạnh, tính cạnh và cuối cùng là bình sai toàn lưới. Tất cả các bước này được thực hiện theo trình đơn theo phương thức đối thoại người-máy.

- Kiểm tra kết quả xủ lý: Việc xử lý sẽ diễn ra theo từng ca đo, qua từng bước phải kiểm tra, đảm bảo thành quả của từng bước đáp ứng chất lượng cho bước sau. Việc bình sai toàn lưới (kết hợp các ca đo) chỉ được thực hiện khi từng ca đo được xử lý đạt yêu cầu.

Sau khi tích hợp các phương trình chuẩn, việc tính toán chuyển dịch được thực hiện theo hai phương án: chuyển dịch tuyệt đối (bảng 3) và chuyển dịch tương đối (bảng 4).

Bảng 3. Vận tốc chuyển dịch tuyệt đối

\begin{tabular}{|c|c|c|c|c|c|c|c|}
\hline \multicolumn{8}{|c|}{ Đơn vị tính: mm/năm } \\
\hline Điểm & Tọa độ & Vận tốc & Sai số & Điểm & Tọa độ & Vận tốc & Sai số \\
\hline \multirow[t]{3}{*}{ HN01 } & Cao (VU) & $-8,0$ & 3,7 & HN05 & $\mathrm{Cao}$ (VU) & 11,3 & 0,3 \\
\hline & Bắc (VN) & $-5,4$ & 0,7 & & Bắc (VN) & $-6,6$ & 0,1 \\
\hline & Đông (VE) & 33,0 & 0,8 & & Đông (VE) & 33,8 & 0,1 \\
\hline \multirow[t]{3}{*}{ HN02 } & Cao (VU) & 10,7 & 0,3 & HN06 & Cao (VU) & 10,6 & 0,3 \\
\hline & Bắc (VN) & $-6,0$ & 0,1 & & Bắc (VN) & $-6,4$ & 0,1 \\
\hline & Đông (VE) & 33,5 & 0,1 & & Đông (VE) & 33,3 & 0,1 \\
\hline \multirow[t]{3}{*}{ HN03 } & Cao (VU) & 8,1 & 0,5 & HN07 & Cao (VU) & 11,5 & 0,3 \\
\hline & Bắc (VN) & $-6,7$ & 0,1 & & Bắc (VN) & $-6,9$ & 0,1 \\
\hline & Đông (VE) & 34,5 & 0,1 & & Đông (VE) & 33,9 & 0,1 \\
\hline \multirow[t]{3}{*}{ HN04 } & Cao (VU) & 5,8 & 0,3 & HN08 & Cao (VU) & 10,1 & 0,4 \\
\hline & Bắc (VN) & $-6,0$ & 0,1 & & Bắc (VN) & $-6,2$ & 0,1 \\
\hline & Đông (VE) & 33,1 & 0,1 & & Đông (VE) & 34,0 & 0,1 \\
\hline
\end{tabular}

Bảng 4. Vận tốc chuyển dịch tương đối

\begin{tabular}{|c|c|c|c|c|c|c|c|}
\hline \multirow{2}{*}{ Điểm } & \multirow[b]{2}{*}{ Tọa độ } & \multirow[b]{2}{*}{ Vận tốc } & \multirow[b]{2}{*}{ Sai số } & \multirow{2}{*}{ Điểm } & \multirow[b]{2}{*}{ Tọa độ } & \multicolumn{2}{|c|}{ Đon vị linn mm/n } \\
\hline & & & & & & Vận tốc & Sai số \\
\hline \multirow[t]{3}{*}{ HN02 } & $\mathrm{Cao}(\mathrm{VU})$ & $-0,8$ & 0,1 & \multirow[t]{3}{*}{ HN06 } & $\mathrm{Cao}(\mathrm{VU})$ & 0,3 & 0,1 \\
\hline & Bắc (VN) & 0,4 & 0,0 & & Bắc (VN) & 0,8 & 0,0 \\
\hline & Đông (VE) & 0,2 & 0,0 & & Đông (VE) & 0,4 & 0,0 \\
\hline \multirow[t]{3}{*}{ HN03 } & Cao (VU) & $-2,6$ & 0,1 & \multirow[t]{3}{*}{ HN07 } & Cao (VU) & 1,3 & 0,1 \\
\hline & Bắc (VN) & $-0,3$ & 0,0 & & Bắc (VN) & 0,0 & 0,0 \\
\hline & Đông (VE) & 1,2 & 0,0 & & Đông (VE) & $-0,1$ & 0,0 \\
\hline \multirow[t]{3}{*}{ HNO4 } & Cao (VU) & $-4,8$ & 0,1 & \multirow[t]{3}{*}{ HN08 } & Cao (VU) & $-1,4$ & 0,1 \\
\hline & Bắc (VN) & 0,4 & 0,0 & & Bắc (VN) & $-0,1$ & 0,0 \\
\hline & Đông (VE) & $-0,4$ & 0,0 & & Đông (VE) & 0,6 & 0,0 \\
\hline
\end{tabular}

Xin lưu ý,vì điểm HN05 được chọn là điểm cố định (không chuyển dịch), điểm HN01 có khoảng thời gian để tính vận tốc quá ngắn (2005-2006) nên không được thống kê trong bảng 4 .

Sai số trình bày ở bảng 3,4 là sai số do phần mềm thông báo. Sai số xử lý theo phần mềm Bernese thường "quá chính xác", không sát với thực tế. Tuy vậy, vẫn thể hiện vận tốc được xác định với độ chính xác cao do khoảng thời gian tương đối dài (10 năm) và khối lượng số liệu tương đối lớn (4 chu kỳ).

Trên cơ sở số liệu bảng 3, 4 sơ đồ vec tơ chuyển dịch tuyệt đối được trình bày ở hình 2 , vec tơ chuyển dịch tương đối được trình bày ở hình 3 . 


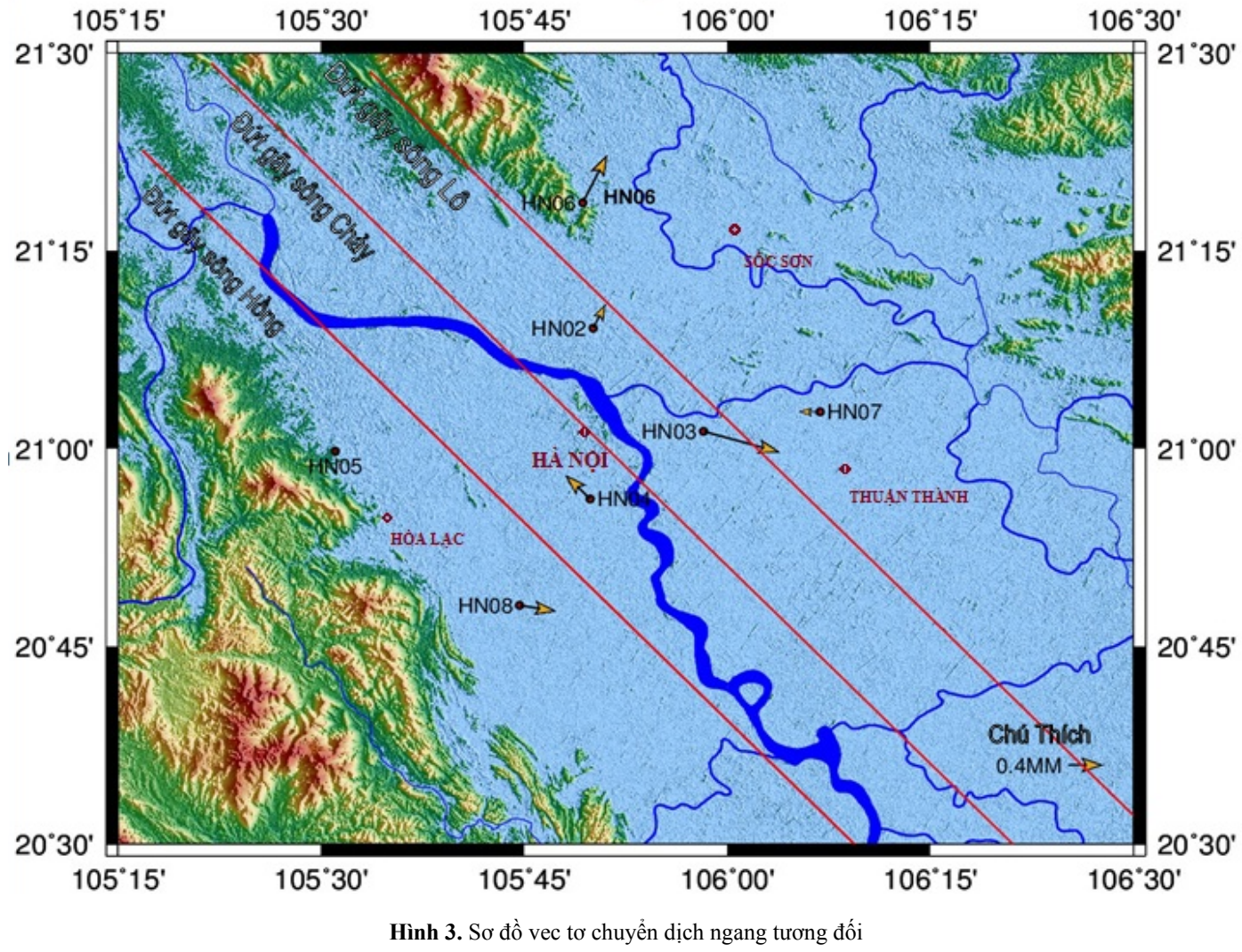

\section{Thảo luận}

Quá trình thảo luận dựa trên kết quả tập hợp từ các dự án, đề tài liên quan và kết quả xử lý ở phần 2, dọc đứt gãy Sông Hồng, theo chiều bắc đến nam lần lượt từ lưới Thác Bà, Tam Đảo - $\mathrm{Ba}$ Vì và lưới khu vực Hà Nội.

Để có thể kết luận về chuyển dịch cần tiến hành phân tích, so sánh kết quả trên các cơ sở sau: (i) chất lượng số liệu đo; (ii) độ chính xác, độ tin cậy kết quả xử lý; iii. chú ý tới độ dài khoảng thời gian giữa chu kỳ đầu và chu kỳ cuối.

Với các quan điểm như trên, cho dù 3 lưới thực hiện theo các đề án, đề tài khác nhau song có thể thấy:

- Mốc được thi công với các phương án thích hợp, hạn chế các ảnh hưởng ngoại sinh, với xác suất lớn phản ánh chuyển dịch vỏ Trái đất.

- Số liệu đều được quan trắc bằng máy thu 2 tần, theo quy trình đo đặc biệt đáp ứng yêu cầu nghiên cứu địa động lực. Số ca đo đủ lớn, độ dài ca đo đủ dài.

- Số liệu đã được xử lý bằng phần mềm được thừa nhận trên trường quốc tế với quy trình chặt chẽ và bề dày kinh nghiệm, đạt độ chính xác cao nhất có thể, có độ tin cậy cao.

- Thời gian giữa chu kỳ đầu tới chu kỳ cuối xấp xỉ 10 năm, phần nào đáp ứng được yêu cầu quan trắc chuyển dịch vỏ Trái đất.

Cũng cần lưu ý, vectỏ vận tốc chuyển dịch xác định từ xử lý số liệu GNSS bao gồm: thành phần chuyển dịch vỏ Trái đất mang tính hệ thống có vận tốc ổn định theo thời gian; thành phần chuyển dịch do các yếu tố ngoại sinh mang tính ngẫu nhiên; cuối cùng là sai số. Khi khoảng thời gian giữa chu kỳ đầu và cuối đủ dài, các thành phần ngẫu nhiên nhỏ không đáng kể so với giá trị hệ thống, đặc trưng cho xu thế chuyển dịch. Trên cơ sở đó, xem xét chi tiết có thể nhìn nhận như sau. 
Tạp chí Các Khoa học về Trái Đất, 38 (1), 14-21

\subsection{Về chuyển dịch tuyệt đối}

Theo (Ngô Văn Liêm, 2011), vector chuyển dịch tuyệt đối xấp xỉ 32 mm/năm trong ITRF05. Theo (Vy Quốc Hải, 2009), vỏ Trái đất khu vực lưới Tam Đảo - Ba Vì chuyển dịch xấp xỉ 36 $\mathrm{mm} / \mathrm{năm}$ trong ITRF00. Theo tính toán phần 2 , điểm HN05 (đại diện cho khu vực lưới Hà Nội) chuyển dịch xấp xỉ 34 mm/năm trong ITRF05. Cân nhắc tới độ lớn sai số thực khi xác định vận tốc tuyệt đối (một vài $\mathrm{mm}$ ) và khác biệt dù nhỏ vận tốc trong các ITRF, có thể cho rằng các giá trị trên là đồng nhất. Vì chuyển dịch tuyệt đối có giá trị lớn, thành phần ngẫu nhiên (sai số, chuyển dịch do nguyên nhân ngoại sinh) nhỏ hơn hẳn nên chỉ rõ $\mathrm{xu}$ thế, chuyển dịch mang hướng đông nam (á vĩ tuyến).

\subsection{Về chuyển dịch tuơng đối}

Theo (Ngô Văn Liêm, 2011), ĐGSH khu vực Thác Bà hoạt động yếu với tốc độ chuyển dịch nhỏ hơn $1 \mathrm{~mm} / \mathrm{năm}$. Theo (Vy Quốc Hải, Trần Đình Tô và Ngô Văn Liêm, 2011), vận tốc chuyển dịch tương đối đứt gãy Sông Hồng (khu vực lưới Tam Đảo - $\mathrm{Ba} V i)$ theo mặt bằng không quá 1,0 $\mathrm{mm} / \mathrm{năm}$. Về ý nghĩa tuyệt đối các giá trị này phản ảnh chuyển dịch nhỏ và cơ bản ở mức xấp xỉ 3 lần sai số (thực tế) xác định chúng. Theo tính toán ở phần 2, theo chiều đông chuyển dịch lớn nhất tại điểm HN03 là $1,2 \mathrm{~mm} / \mathrm{năm}$, còn tại các điểm khác giá trị này đều nhỏ hơn $1 \mathrm{~mm} /$ năm. Tổng hợp các kết quả trên cho thấy rằng: trên cả ba khu vực (liên quan tới 2 đoạn: đoạn Manpan-Việt Trì và đoạn Việt Trì-Vịnh Bắc Bộ của ĐGSH (Nguyễn Đăng Túc, 2002) chuyển dịch tương đối có giá trị nhỏ, xấp xỉ $1 \mathrm{~mm} /$ năm. Về xu thế, vì chuyển dịch bé, các thành phần hệ thống và ngẫu nhiên khó có thể phân biệt, nên các vec tơ chưa chỉ ra xu thế rõ ràng. Bởi vậy, đặc điểm chuyển dịch phải có xu thế tách giãn của ĐGSH chỉ nên coi là khả năng có thể, cần chu kỳ đo có thời gian dài hơn.

\section{Kết luận}

Lần đầu tiên, chuyển dịch hiện đại ĐGSH được đánh giá, bàn luận theo phân đoạn đứt gãy, trên cơ sở xử lý số liệu quan trắc của các lưới Thác Bà, lưới Tam Đảo - Ba Vì và lưới khu vực Hà Nội.

Cho dù ba lưới được thiết lập, thu thập, xử lý số liệu theo các đề tài dự án khác nhau, song có thể nói, khối lượng số liệu thu thập đủ lớn trong khoảng thời gian tương đối dài, được xử lý bằng phần mềm tiên tiến. Đây là tiền đề quan trọng đảm bảo kết quả xử lý đạt độ chính xác và các kết luận có độ tin cậy.

Qua phân tích và tổng hợp kết quả xử lý 3 lưới Thác Bà, lưới Tam Đảo - Ba Vì, lưới khu vực Hà Nội trên khu vực nghiên cứu bao trùm 2 đoạn: Manpan - Việt Trì, Việt Trì - Vịnh Bắc Bộ có thể thấy rằng:

- Khu vực nghiên cứu có chuyển dịch tuyệt đối trung bình xấp xỉ $34 \mathrm{~mm} /$ năm, hướng á vĩ tuyến.

- Chuyển dịch tương đối dọc theo ĐGSH xấp xỉ $1 \mathrm{~mm} / \mathrm{năm}$.

Vận tốc chuyển dịch xác định từ số liệu GNSS hoàn toàn độc lập, đây là dữ liệu quan trọng phục vụ cho các chuyên ngành so sánh cũng như minh giải theo các số, dữ liệu địa chất.

Kết quả tương đối đồng nhất được tập hợp từ 3 lưới riêng rẽ là minh chứng cho tính hiệu quả, độ chính xác, độ tin cậy cao của phương pháp GNSS trong nghiên cứu địa động lực hiện đại. Với vai trò của đứt gãy Sông Hồng trong bình đồ kiến tạo Việt Nam, các kết quả trên là các dữ liệu tham khảo hữu ích cho việc nghiên cứu các đứt gãy khác ở nước ta.

\section{Lời cảm ơn}

Công việc nghiên cứu của nhóm tác giả và dữ liệu đo GPS lưới khu vực Hà Nội các năm 2013, 2015 được thực hiện trong khuôn khổ của đề tài độc lập cấp Nhà nước mã số ĐTĐL.2012-T.28 và sự hồ trợ của Phòng Địa động lực hiện đại - Viện Địa chất. Xin chân thành cảm ơn sự giúp đỡ của Ông Nguyễn Tuấn Anh, chủ trì nhiệm vụ "Xây dựng hệ thống các điểm Trắc địa sử dụng công nghệ GPS độ chính xác cao trong việc quan trắc biến dạng lớp vỏ Trái đất và cảnh báo thiên tai ở khu vực Việt Nam" đã tạo điều kiện để nhóm nghiên cứu tiếp cận dữ liệu đo lưới khu vực Hà Nội các năm 2005, 2006.

\section{Tài liệu dẫn}

Nguyễn Tuấn Anh (chủ biên), 2006: Dự án sản xuất thử nghiệm "Xây dựng hệ thống các điểm Trắc địa sử dụng công nghệ GPS độ chính xác cao trong việc quan trắc biến dạng lớp vỏ Trái đất và cảnh báo thiên tai ở khu vực Việt Nam". 
V.Q. Hải và nnk/Tạp chí Các Khoa học về Trái Đất, Tập 38 (2016)

Lưu trữ tại Viện Khoa học đo đạc và bản đồ, Ngô Văn Liêm, 2011: Đặc điểm phát triển địa hình trong mối Hà Nội.

Vy Quốc Hải, 2009: Xác định chuyển dịch tuyệt đối khu vực lưới GPS Tam Đảo - Ba Vì, Tạp chí Địa chất số 311, 3-4, tr.22-30.

Vy Quốc Hải, Trần Đình Tô và Ngô Văn Liêm, 2011: Xác định chuyển dịch hiện đại đới đứt gãy Sông Hồng theo số liệu lưới GPS Tam Đảo - Ba Vì (1994-2007). Tạp chí Các Khoa học về Trái Đất, tr.474-479. liên quan với địa động lực hiện đại đới đứt gãy Sông Hồng. Luận án Tiến sỹ Địa lý, Hà Nội. Lưu trữ Thư viện Viện Địa chất, Hà Nội.

Nguyễn Đăng Túc, 2002: Một số đặc điểm tân kiến tạo hệ đứt gãy Sông Hồng-Sông Chảy. Luận án Tiến sĩ, Hà Nội. Lưu trữ Thư viện Quốc gia, Hà Nội.

Rolf Dach, Urs Hugentober and Peter Walser, 2008: Bernese GPS Software Version 5.0. Astronomical Institute, University of Bern. 